\title{
A Influência Estrangeira e as Ideias de Bernardo Souza Franco sobre a Questão Bancária no Âmbito Regional e Nacional: Pará-Brasil (1846-1848)*
}

\section{The Foreign Influence and the Ideas of Bernardo Souza Franco on Regional and National Banking: Pará-Brazil (1846-1848)}

Thiago Fontelas Rosado Gambia ${ }^{\text {[i }}$

\begin{abstract}
Resumo: Este estudo explora as ideias de Souza Franco sobre a questão bancária em âmbito regional e nacional e, com base nisso, objetiva apresentar seu diagnóstico sobre o sistema bancário brasileiro, analisar seus argumentos em defesa da criação de bancos no Brasil e na província do Pará e identificar aspectos que indiquem a assimilação de ideias e experiências estrangeiras e sua adaptação à realidade brasileira. No primeiro caso, analisa-se uma série de cinco artigos sobre a criação de um banco comercial na província do Pará publicados em 1846 no jornal paraense Treze de Maio. No segundo caso, consideram-se o diagnóstico e a proposta sobre o sistema bancário brasileiro apresentados no livro Os bancos do Brasil, publicado originalmente em 1848. A argumentação de Souza Franco apresentada nos textos analisados neste trabalho revelam que as ideias econômicas estrangeiras eram conhecidas, assim como as experiências vindas do exterior. Esse conhecimento era assimilado criticamente e adaptado às circunstâncias regionais e nacionais. Considerar as ideias de Souza Franco baseadas em assimilações críticas e adaptações de ideias e experiências estrangeiras não implica dizer que elas significassem mudanças qualitativas na estrutura econômica e política do império.
\end{abstract}

Palavras-chave: Bancos. Souza Franco. Pará. Brasil. Pensamento econômico brasileiro.

\begin{abstract}
This paper deals with Souza Franco's ideas on banking at regional and national levels. It aims to present his diagnosis on the Brazilian banking system; to analyze his arguments in defense of the creation of banks in Brazil and in the province of Pará; and to identify aspects that indicate the assimilation of foreign ideas and experiences and their adaptation to the Brazilian reality. In the first case, it will be analyzed a series of five articles on the creation of a commercial bank in the province of Pará published in 1846 in Treze de Maio, a local newspaper. In the second case, it will be considered the diagnosis and proposal on the Brazilian banking system presented in the book Os bancos do Brasil (The banks of Brazil), originally published in 1848. The arguments of Souza Franco presented in the texts analyzed in this paper reveal that foreign economic ideas were known as well as the experiences coming from abroad. This knowledge was critically assimilated and adapted to
\end{abstract}

\footnotetext{
* $\quad$ Este trabalho contou com o apoio da Fundação de Amparo à Pesquisa do Estado de Minas Gerais (FAPEMIG).

a Universidade Federal de Alfenas (Unifal-MG), Instituto de Ciências Sociais Aplicadas, Programa de Pós-Graduação em Economia. Varginha, Minas Gerais, Brasil.
} 
regional and national circumstances. However, it does not imply that this meant qualitative changes in the economic and political structure of the Brazilian empire.

Keywords: Banks. Souza Franco. Pará. Brazil. Brazilian economic thought.

JEL Classification: B31; N46.

\section{Introdução}

No conhecido capítulo de Formação econômica do Brasil, em que compara Cairu e Hamilton, Celso Furtado (2007) afirma que as ideias econômicas debatidas em terras brasileiras eram praticamente uma cópia da economia política liberal já avançada na Europa. Diante dessa afirmação, é possível dizer que não faria sentido para os estudiosos do pensamento econômico brasileiro ocupar-se com o século XIX. Entretanto, outros autores chamam a atenção para a importância do estudo do pensamento econômico brasileiro no século XIX, pois criticam a visão de que tal pensamento significava mera cópia do europeu. Portanto, trazem o recorte de suas análises para o oitocentos e discutem a adaptação de ideias estrangeiras no país e a originalidade das ideias econômicas nacionais.

Hugon (1994), ao avaliar que as ideias econômicas debatidas no Brasil estavam alicerçadas nas condições e nas necessidades da economia nacional, considera a ciência econômica no Brasil liberal, nacionalista, comercialista e industrialista, uma "doutrina especificamente brasileira" (HUGON, 1994, p. 348). Na mesma linha, Beauclair (2001, p. 219) dirá que o pensamento econômico brasileiro no século XIX era “[...] profundamente original, fruto de preocupações com questões concretas existentes numa economia pré-industrial, ou, como se queira, de base não industrial [...]”. Gremaud (1997) também observa o movimento de adaptação de ideias estrangeiras à realidade nacional desde a efetivação dos primeiros cursos de economia política no Brasil inseridos no currículo das faculdades de direito e engenharia.

Do mesmo modo, ao analisar os debates parlamentares e os relatórios das crises financeiras de meados do século XIX, não é difícil perceber que as ideias econômicas estrangeiras afluíam para o Brasil e eram assimiladas e adaptadas pelos políticos que deles participavam (SÁEZ, 2008, 2013). Anteriormente, Saes (1986) já havia indicado que, nesses debates, o pensamento europeu que chegava ao país era processado para dar conta dos problemas peculiares da realidade brasileira. Em suma, os autores referidos encontram no pensamento econômico brasileiro traços da adaptação original característica de países da periferia do capitalismo (CARDOSO, 1997, 2001).

Se o pensamento econômico brasileiro no XIX era adaptado e original, cabe mostrar como a assimilação e adaptação do pensamento econômico estrangeiro se processava no país. Gremaud (1997) e Corrêa (2015) desenvolveram estudos 
nessa linha ao mostrarem a influência das ideias de Henry Dunning MacLeod no Brasil. Enquanto o primeiro enfatizou o ensino na faculdade de Direito de São Paulo, o segundo ampliou o escopo e abordou a influência do autor escocês sobre Bernardo de Souza Franco na década de 1860. Neste caso, o estudo do pensamento econômico brasileiro se liga necessariamente às questões econômicas e financeiras, especialmente quanto à moeda, ao crédito e aos bancos.

Bernardo de Souza Franco foi um dos políticos mais destacados do império brasileiro. A partir do Legislativo e do Executivo, como deputado, senador e ministro da fazenda participou ativamente do debate econômico no país entre os chamados metalistas e papelistas em meados do século XIX. Membro do partido liberal, com raízes na distante província do Pará, Souza Franco cerrou fileira entre os chamados papelistas na defesa da pluralidade de emissão bancária, da flexibilidade do padrão-ouro e, consequentemente, da ampliação da oferta de crédito para azeitar a engrenagem produtiva e comercial do império.

Este estudo explora as ideias de Souza Franco sobre a questão bancária em âmbito regional e nacional com os seguintes objetivos: apresentar seu diagnóstico sobre o sistema bancário brasileiro; analisar seus argumentos em defesa da criação de bancos no Brasil e na província do Pará; e identificar aspectos que indiquem a assimilação de ideias e experiências estrangeiras e sua adaptação à realidade brasileira. Para alcançar esses objetivos, analisa-se uma série de cinco artigos sobre a criação de um banco comercial na província do Pará publicados, em 1846, no jornal paraense Treze de Maio, bem como o diagnóstico e a proposta sobre o sistema bancário brasileiro apresentados no livro Os bancos do Brasil, publicado originalmente em 1848.

\section{Souza Franco: Notas Biográficas, Ideias Econômicas e Contexto da Eco- nomia Brasileira na Década de 1840}

Souza Franco foi um importante político do império brasileiro. Nascido em Belém do Pará, desde cedo se envolveu em questões políticas. De acordo com as notas biográficas fornecidas por Vasconcellos e Smith de Vasconcellos (1918) e Macedo (1876), aos 18 anos, em meio à luta entre brasileiros e portugueses pela independência do Brasil, foi acusado de conspirar contra Portugal, que, em 1823, ainda mantinha tropas em sua província. Preso, embarcou na galera Andorinha do Tejo em direção à fortaleza de São Julião, em Lisboa, na condição de deportado. Retornou ao Pará no ano seguinte, já com certa fama política, porém acabou atrás do balcão do armazém do pai, o negociante Manoel João Franco, servindo-lhe como caixeiro. Em 1831, partiu para Olinda, onde trabalhou como jornalista na redação do A voz do Biberibe e como colaborador no Diário de Pernambuco. Formou-se, em 1835, em Ciências Jurídicas e Sociais, na Faculdade de Direito. 
Se o curso de economia política, no âmbito do curso de Direito, foi oferecido pela primeira vez em 1832 e se Souza Franco se formou em 1835, é provável que tenha assistido às aulas de Pedro Autran da Mata Albuquerque, primeiro catedrático da matéria, formado em direito em Aix, na França, e influenciado por James Mill (GREMAUD, 2000). Em suas Preleções de Economia Política, livro publicado em 1859, Mata Albuquerque (apud GREMAUD, 2000) sustentava que, em última instância, a moeda deveria ser lastreada em metais. No entanto, para driblar a limitação imposta à emissão de moeda por uma eventual escassez de metais, a melhor alternativa seria substituir a moeda metálica pela emissão de bancos: títulos e notas conversíveis em metal. Essa emissão, além de dar maior flexibilidade à oferta monetária, reduziria a quantidade de metais necessários para lastrear a circulação, uma vez que seria um múltiplo do fundo de reserva metálica dos bancos. A escassa moeda metálica deveria ser utilizada principalmente para os pagamentos ao exterior, e não na circulação interna.

O grande entrave a essa circulação seria o entesouramento, causa da estagnação dos negócios. Para evitá-la, Mata Albuquerque propunha a criação de bancos que pudessem preencher esse vazio monetário por meio da intermediação de parte dessa riqueza acumulada e de suas próprias emissões. As emissões em si seriam uma forma de crédito que contribuiria para o aumento da produção e, além disso, pouparia metais.

Os bancos de depósito e emissão, portanto, seriam instrumentos importantes para a dinâmica da economia e, por isso, Mata Albuquerque aponta o regime de liberdade bancária nos moldes escoceses como o mais adequado para o Brasil. Em que pese o risco de emissão excessiva, o alargamento da oferta monetária e do crédito contribuiria para o mais importante, isto é, a queda dos juros e o aumento do emprego produtivo de capitais (GREMAUD, 2000, p. 13-15).

Essas ideias econômicas, próximas da escola bancária inglesa, podem ter permanecido em Souza Franco como reminiscências. Terminado o curso de Direito, e de volta à província natal, trabalhou como procurador fiscal da tesouraria e juiz civil em Belém. Sua verve política manteve-se viva e elegeu-se deputado pelo Pará em 1838, curiosamente filiado ao partido conservador, uma vez que ficará conhecido como um dos expoentes do partido liberal. Souza Franco transferiu-se para esse partido apenas em 1843 porque, segundo Macedo (1876, p. 149), não concordava com os excessos dos conservadores depois da revolta liberal de 1842.

Schulz (2013, p. 16) o considera a principal liderança liberal em matéria financeira e o identifica com as elites provinciais contra a estratégia dos conservadores que buscava centralizar o poder político na corte. O autor o situa, junto com Mauá, em uma ala progressista dentro do campo político do império. Estar na ala progressista significava, ainda segundo Schulz, defender a autonomia provincial, 
a pluralidade de emissão bancária, os interesses ligados às ferrovias e à criação de indústrias e, finalmente, a abolição gradual da escravidão (SCHULZ, 2013, p. 17).

Fonseca (2012) e Salomão (2013) também vinculam Souza Franco a ideias que poderíamos chamar de progressistas. O papelismo, do qual era representante, é visto por esses autores como o polo heterodoxo do debate financeiro de meados do século XIX, uma vez que o associam à maior flexibilidade em relação ao déficit público e ao estímulo à atividade produtiva e comercial como objetivo de fundo. Enxergam nele uma das correntes que formariam o pensamento desenvolvimentista latino-americano no século XX, ao lado do nacionalismo e da industrialização. Embora noções como progressista ou desenvolvimentista talvez não estivessem no horizonte do império, é possível situar Souza Franco no campo da crítica à centralização do poder político e da ortodoxia econômica. Dessa forma consolidou sua carreira política.

Depois de passar pela presidência da província do Pará, em 1839, assumiu a direção da província de Alagoas, em 1844, já no partido liberal. Em 1846, escreveu os artigos em defesa da criação de um banco comercial no Pará e, em 1848, ano em que ocupou o ministério dos negócios estrangeiros no gabinete Paula Souza e assumiu interinamente por um mês o ministério da fazenda, publicou Os bancos do Brasil.

\section{As Ideias Econômicas de Souza Franco em seu Contexto}

A década de 1840 foi especialmente importante para as questões monetárias e bancárias no Brasil. Em 1846, a câmara dos deputados aprovou a lei que estabelecia a paridade do mil-réis com o ouro e colocou o país, pelo menos de jure, no regime do padrão-ouro, tornando obrigatória a conversibilidade da moeda em metal. Além disso, autorizava o governo a reduzir a oferta monetária a fim de manter o valor estabelecido legalmente. No entanto, a lei de 1846 não era um problema para Souza Franco. Primeiro porque era um defensor da conversibilidade da moeda em metal sempre que as condições permitissem. Ele também se preocupava com a estabilidade do valor da moeda e sustentava que a "[...] circulação metálica, ou sob base metálica, e papel bancário realizável à vontade do portador, é preferível a de papel não realizável do tesouro e à própria circulação metálica [...]" (FRANCO, 1984, p. 85-87). Embora papelista, não se enquadrava entre os chamados papelistas puros (VILLELA, 1999, 2001), que defendiam a moeda fiduciária, e não seria aceitável a instabilidade permanente do valor da moeda em nome da ampliação da oferta de crédito. Nota-se uma atuação concreta nesse sentido nas medidas que tomou como ministro da fazenda durante a crise de 1857. Segundo porque, para Souza Franco, o câmbio não guardava relação tão direta com a oferta monetária. Assim, sua expansão não era considerada por 
ele como a causadora imediata de uma desvalorização cambial e, consequentemente, do abandono do padrão-ouro. Na verdade, ele e outros comerciantes que deram depoimento nos relatórios das comissões de inquérito sobre as crises de 1857 e 1864 consideravam a flutuação do câmbio atrelada mais ao resultado do balanço de pagamentos do que à oferta monetária. Porém, é evidente que a exigência legal expunha um conflito básico da realidade econômica brasileira da época entre a necessidade de recursos para viabilizar a realização dos negócios e a estabilidade do valor do meio circulante em relação à paridade. O essencial não era necessariamente o rompimento com o padrão-ouro, mas a administração mais flexível da oferta monetária em compasso com o volume dos negócios (VILLELA, 2001, p. 91).

Também na década de 1840 foram criados vários bancos nas províncias. Embora o Banco Comercial do Rio de Janeiro seja de 1838, seus estatutos foram aprovados somente em 1842. Depois desse surgiram outros bancos nas províncias da Bahia (1845), do Maranhão (1846) e de Pernambuco (1851). O Banco do Pará foi criado em 1846, mesma época em que estavam sendo publicados os escritos de Souza Franco no jornal Treze de Maio. Todas essas iniciativas eram de caráter privado e frequentemente levadas a cabo pelas associações comerciais das províncias em comum acordo com os respectivos governos locais (RIDINGS, 1994; LEVY; ANDRADE, 1985).

Entre 1808 e 1836, prevaleceu no Brasil a unidade emissão. Com a criação desses bancos emissores provinciais, o país viveu uma experiência de pluralidade emissora. Com isso, o assunto voltou a ser debatido diante do vácuo de uma legislação específica sobre a criação e operação de bancos. O caso do Banco Comercial do Rio de Janeiro é um exemplo, porque funcionou informalmente durante quatro anos até que as autoridades formalizassem sua atuação por meio da aprovação de seus estatutos. O debate da pluralidade, por sua vez, remetia à reforma monetária e apresentava a necessidade de se discutir conjuntamente uma reforma bancária coerente com ela, pois ambas estavam interligadas. Surgiu daí o embate político entre a corte e as províncias, que se refletiu no debate financeiro de meados do século XIX.

A atuação parlamentar de Souza Franco foi coerente com as ideias econômicas que divulgou em sua obra de 1848 e, como dissemos, o colocava no campo da crítica ao metalismo e aos "amadores da moeda metálica" (FRANCO, 1846b, p. 2). Se tivéssemos que resumir em poucas palavras suas ideias mais gerais sobre bancos, seriam, nesta ordem: aumento da oferta de crédito, pluralidade de emissão e conversibilidade do meio circulante. No plano teórico, essas ideias o aproximavam da escola bancária inglesa. No plano político, o situavam ao lado dos defensores dos interesses provinciais e dos críticos à centralização do poder na corte. Economia e política andam juntas em Souza Franco, pois as ideias de bancos provinciais 
e pluralidade de emissão não podem ser desvinculadas da ideia de autonomia provincial.

Em sua visão, os bancos seriam peças importantes da dinâmica econômica ao desempenhar seu papel clássico de intermediário entre poupadores e investidores. Essas instituições seriam capazes de atrair o capital entesourado, guardado nas "burras e gavetas" (FRANCO, 1846b, p. 1), e colocá-lo à disposição dos negócios, favorecendo, assim, poupadores, investidores, acionistas dos bancos e a economia de maneira geral. Um exemplo de concretização dessa ideia é a Lei n ${ }^{\circ} 906$, de 10 de agosto de 1857, que autorizava o governo a depositar os recursos disponíveis no tesouro e nas tesourarias provinciais em contas-correntes remuneradas do Banco do Brasil e de suas caixas filiais. Como veremos na discussão do caso do Pará, para Souza Franco não fazia sentido manter recursos parados nos cofres públicos ou privados em um quadro frequente de escassez de moeda e crédito.

Contudo, não se tratava apenas de bancos de depósito, mas sim de bancos de depósito e emissão. As emissões bancárias deveriam estar na base do crédito, pois, nas contas de Souza Franco, mesmo que os bancos conseguissem atrair os capitais entesourados, os depósitos não seriam suficientes para atender a demanda em todas as praças. A realidade brasileira era diferente da europeia e estadunidense.

A princípio, Souza Franco acreditava que o próprio mercado seria suficiente para estabelecer o compasso entre oferta de moeda e necessidades do comércio. Porém, reconhecia que os bancos emissores podiam ajudar ou atrapalhar o governo na administração do meio circulante e no desenvolvimento da riqueza pública. Ajudavam quando forneciam moeda na medida da necessidade dos mercados e mantinham o seu valor o mais estável possível. Atrapalhavam quando, na tentativa imprudente de auferir lucros maiores, excediam as emissões e ampliavam a oferta monetária para além das necessidades do mercado. Por isso, como mencionado, o funcionamento dos bancos deveria ser autorizado pelo governo e suas operações estritamente acompanhadas por ele.

Além disso, na sessão da câmara de 25 de abril de 1850 (CÂMARA DOS DEPUTADOS, 1879, p. 481-482), Souza Franco dizia que, quando um banco particular estivesse ligado aos interesses do Estado, como na questão do meio circulante, o governo deveria dar garantias e privilégios a essa instituição. Portanto, distanciando-se nesse aspecto de Mata Albuquerque, Souza Franco não fazia a defesa dos bancos livres, mas de uma emissão plural e controlada entre o monopólio puro e a liberdade ilimitada.

No diagnóstico de Souza Franco, os maiores problemas da economia brasileira em meados do século XIX eram os juros altos, o curto prazo dos empréstimos e a escassez de meio circulante. Os juros seriam altos porque haveria excesso de demanda em relação à oferta de capital. No entanto, a insuficiência de capital não seria consequência apenas de sua escassez, mas também da organização de- 
ficiente das instituições de crédito no país, que não eram capazes de atraí-lo para aplicações produtivas. Como mencionado anteriormente, e como se verá na argumentação em defesa da criação de um banco no Pará, a oferta de capital poderia ser ampliada por meio da captação dos recursos públicos e privados entesourados. Porém, não se tratava apenas dos bancos emissores já conhecidos adequados ao crédito de curto prazo demandado pelo comércio, era preciso criar instituições capazes de fornecer o crédito de longo prazo mais adequado para as atividades agrícola e manufatureira. Naquela altura, os bancos hipotecários existentes não cumpriam o papel de emprestar em longo prazo. O Banco Rural e Hipotecário, por exemplo, fez poucos empréstimos desse tipo apesar do nome (GUIMARÃES, 1999).

Quanto ao meio circulante, Souza Franco via duas possibilidades de atender a necessidade dos mercados de acordo com o volume das transações: o tesouro e os bancos emissores privados. Se o tesouro não fosse capaz de fornecer adequadamente o meio circulante, a solução passaria pela criação de mais estabelecimentos de crédito, além dos bancos comerciais. Só assim conseguiriam cumprir o duplo objetivo de fornecer crédito à agricultura e manufatura e meio circulante aos mercados, como afirmou na sessão da câmara dos deputados de 13 de junho de 1857 (CÂMARA DOS DEPUTADOS, 1857, p. 248-252). Contudo, não se tratava da defesa de uma proliferação de bancos.

Souza Franco, como nos referimos anteriormente, censurava a criação sem controle de bancos para remediar o problema da escassez de meio circulante e crédito, o que seria desnecessário ou, mesmo, inconveniente. Não se tratava, portanto, de uma saída como a escocesa ou a estadunidense. Ficava clara a opção pela pluralidade emissora, mas não por uma completa liberdade de emissão: “[...] ninguém tire dos meus princípios a conclusão de que quero a completa liberdade de oferta; não está isto em meus princípios [...]" (CÂMARA DOS DEPUTADOS, 1857, p. 250).

Defendia o estabelecimento de bancos na corte e nas províncias em que pudessem ser criados e sustentados. Como veremos, a viabilidade e a capilaridade territorial dos negócios era uma preocupação de Souza Franco e ele tratará disso ao analisar o caso paraense na década de 1840. Como o lastro deveria ser parcialmente metálico, o capital não seria um problema para se criar tais bancos, que poderiam contar também com títulos públicos para a reserva, como ensinavam os casos da Inglaterra e dos Estados Unidos (CÂMARA DOS DEPUTADOS, 1879, p. 481).

A argumentação papelista apoiava-se frequentemente em questões práticas atinentes mais à operacionalização da política econômica e menos em teoria (FONSECA, 2012). O próprio Souza Franco (1984) reconhecia que as ideias papelistas, no sentido de promover a dinâmica econômica, estavam ligadas mais aos 
"interesses do comércio" do que à legitimidade de uma doutrina. Por isso, não é estranho que utilizasse exemplos concretos de outros países em sua argumentação e, na discussão da pluralidade, apelasse para a realidade econômica do império para sustentar sua posição (CÂMARA DOS DEPUTADOS, 1879, p. 481).

Entretanto, é preciso considerar que não só a experiência estrangeira balizava a posição de Souza Franco. Como adverte Marx (2013, p. 1004), para o caso do Banco da Inglaterra, os banqueiros ganhavam duas vezes com a emissão de notas lastreadas em títulos públicos: ao receberem do governo os juros dos títulos e ao receberem dos devedores os juros dos empréstimos. Portanto, não se pode deixar de lado o interesse de comerciantes futuros banqueiros na proposta papelista.

Em suma, a maior preocupação de Souza Franco era a dinâmica da economia do império, vinculada aos interesses do comércio, agricultura e manufatura. Sustentava que os principais problemas econômicos de meados do século XIX juros altos, curto prazo do crédito e escassez de meio circulante - poderiam ser resolvidos por meio da criação de bancos emissores na corte e nas províncias. Seguindo ideias papelistas, as notas bancárias deveriam ser lastreadas em metal e títulos públicos. O ponto de Souza Franco era usar os bancos para reunir os capitais dispersos e mortos, posto que entesourados, e colocá-los a serviço do comércio e da produção, seja agrícola ou manufatureira. O maior risco desse arranjo seria o excesso de emissão de notas bancárias decorrente de crises e da má administração dos bancos. Nesse caso, bastaria que o Estado regulamentasse e acompanhasse a atividade bancária.

É possível notar nesse conjunto de ideias sobre moeda, crédito e bancos a influência do debate monetário inglês, no caso a escola bancária, de princípios ensinados por Mata Albuquerque e de experiências estrangeiras concretas. Tais ideias e, portanto, as mesmas influências podem ser detectadas especificamente nos argumentos utilizados nos artigos de 1846 e em Os bancos do Brasil, de 1848 . Para tanto, apresentaremos, a seguir, um arrazoado sobre a defesa da criação de um banco em sua província natal feita por Souza Franco.

\section{A Criação de um Banco Comercial no Pará}

Em 1846, Souza Franco escreveu uma série de cinco artigos, publicados entre fevereiro e março no jornal paraense Treze de Maio, sobre a necessidade de criação de um banco comercial na praça de Belém. Cabe aqui a apresentação e análise dos argumentos utilizados por ele para defender a utilidade das instituições de crédito no desenvolvimento da província para verificar como tratou a questão bancária em âmbito regional, quais influências aparecem nesse discurso e como elas reaparecerão posteriormente na discussão da questão em âmbito nacional. 
O aparecimento dos artigos de Souza Franco em meados da década de 1840 se enquadra em um movimento mais amplo de criação de bancos provinciais no Brasil, como mencionado anteriormente. Para resolver problemas relativos à escassez de moeda e crédito, houve iniciativas de caráter privado frequentemente levadas a cabo pelas associações comerciais das províncias em comum acordo com os respectivos governos locais. A província do Pará não fugia à regra, e a escassez de moeda e os juros altos pareciam ser os maiores entraves à economia local. O ministro da fazenda Joaquim Francisco Vianna, em 1845, reuniu-se com negociantes e capitalistas locais para discutir uma solução para o problema da escassez de numerário na província. As soluções propostas passavam pelo aumento da emissão de notas do tesouro ou de bancos emissores (TREZE DE MAIO, 1845, p.1). O problema dos juros altos foi apontado pelo próprio Souza Franco, que o atribuía à escassez de capital e de concorrência. Por isso, criticou a lei de 24 de outubro de 1832, que definia que a taxa de juros seria aquela convencionada entre as partes sem estabelecer um limite legal. Com isso, segundo ele, os emprestadores da província passaram a cobrar juros de $3 \%$ a $8 \%$ ao mês, porcentagem muito superior aos $6 \%$ anuais estabelecidos legalmente para casos em que os juros não haviam sido convencionados entre as partes.

A solução para o problema da moeda e do crédito passaria pela criação de um banco comercial na província, como explicava Souza Franco em seus artigos publicados no Treze de Maio. O ponto de partida da argumentação é um modelo um pouco mais amplo do funcionamento da economia, que será retomado em 1848. Peláez e Bulhões (1984), na "Introdução a propósito da intermediação financeira", publicada na segunda edição de Os bancos do Brasil, indicam como era esse modelo: primeiro, a industrialização e a acumulação de capital seriam feitas por instituições de crédito; depois entrariam a mão de obra qualificada e os capitais vindos do exterior, que permitiriam maiores taxas de retorno, acelerariam o crescimento da economia e tornariam o processo autossustentável. Os bancos seriam a chave desse esquema. Os autores dizem que Souza Franco propôs “[...] um sistema de intermediação privada para o financiamento não inflacionário do desenvolvimento econômico [...]" (FRANCO, 1984, p. 4). Vale notar que Peláez e Bulhões usam o termo industrialização em sua introdução. É verdade que Souza Franco usa o termo indústria em seus discursos, todavia se refere a diversas atividades econômicas que corresponderiam ao comércio, agricultura e manufatura.

De fato, no início do primeiro artigo, ele desenvolve um modelo mais ou menos como apresentado por Peláez e Bulhões. Primeiro, há a advertência de que a província precisa de capitais e braços para trabalhar suas terras. A disponibilidade de terras, em sua visão, seria o principal atrativo para investimentos rentáveis. O ponto fundamental do desenvolvimento regional seria o crescimento econômi$\mathrm{co}$, que se traduziria em prosperidade e esta atrairia imigrantes estrangeiros para 
promover a colonização da província. Sua ideia de dinamização do mercado não pode ser desvinculada da ideia de imigração, pois, para ele, "prosperidade atrai prosperidade" e isso significava a atração de pessoas em busca de oportunidades de trabalho e investimento. Então, o capital combinado com a disponibilidade de terra e força de trabalho redundaria em prosperidade e atração de mais imigrantes para a província. Formava-se, assim, um círculo virtuoso de riqueza e civilização que começaria com capital e braços, aumento de lucros e salários e, finalmente, colonização. Nesse esquema, o capital seria a base da colonização, e, portanto, a questão que se apresentava era como aumentar o capital na província.

Souza Franco a respondia com a proposta de criação de um banco comercial em Belém. Vale ressaltar que se tratava de um banco de depósitos e emissão de bilhetes e vales. Esse ponto é muito importante porque, na visão de Souza Franco, ainda não havia no Brasil depósitos suficientes para fornecer a base do crédito, como nos Estados Unidos e na Europa. Por isso, os bancos não poderiam ser apenas de depósitos, deveriam ser também de emissão. Esses bancos comerciais seriam os estabelecimentos capazes de reunir os capitais e ampliá-los por meio do crédito baseado em depósitos e na emissão de bilhetes e vales lastreada em títulos e metais (FRANCO, 1846a, p. 3).

Pela argumentação de Souza Franco, nota-se que o problema de moeda e crédito da província não estava calcado na escassez de capital. Capital havia, porém a riqueza acumulada estava entesourada. O capital estava morto e guardado em "burras e gavetas" de particulares e nos cofres das tesourarias públicas, estorvando o desenvolvimento da riqueza individual e coletiva. Pelas suas contas, ainda que fosse uma aproximação grosseira da realidade, haveria duzentos mil habitantes civilizados na província, dos quais dois mil em condições de poupar. A poupança total desse grupo giraria em torno de mil contos de réis por ano. Se esse recurso fosse empregado em atividades produtivas poderia render $25 \%$ por ano, ou seja, duzentos e cinquenta contos de réis. Era um recurso vultoso. Para se ter uma ideia, a receita da província para o exercício 1844-1845 estava orçada em cento e noventa contos de réis (MORAES, 1845, p. 31). Portanto, a lógica de funcionamento ou a função do banco paraense seria reunir os capitais entesourados, ampliá-los por meio do crédito e colocá-los em circulação. Os bancos vivificariam o capital morto como instrumentos fundamentais na luta contra o entesouramento. Por isso, ele termina o primeiro artigo da série com uma crítica ao entesouramento e o coloca como um embaraço ao desenvolvimento da riqueza da província.

A ideia de que o entesouramento bloqueia o desenvolvimento permanecerá no espírito de Souza Franco. Como se verá em 1857, sua pena de ministro da fazenda assinará a Lei no 906, de 10 de agosto, que autorizará o governo a depositar, no Banco do Brasil e em suas caixas filiais, os recursos disponíveis no tesouro e nas 
tesourarias de fazenda. Será, portanto, a aplicação em âmbito nacional daquilo que já recomendava regionalmente.

Detectada a causa do problema econômico provincial - o entesouramento público e privado - e sua solução - a criação de bancos de depósito e emissão -, Souza Franco passou a se preocupar com a estabilidade e viabilidade desses estabelecimentos na província (FRANCO, 1846b, p. 1). A questão da estabilidade do banco estava intimamente ligada à sua administração. No caso dos bancos, seria preciso que o governo impusesse garantias para que não fossem mal administrados e falissem. Na argumentação de Souza Franco, estavam submetidos a riscos de duas ordens:

a) internamente, o perigo de uma emissão excessiva, isto é, acima de seu fundo de reserva em metais e títulos, como ilustrou com exemplos da Inglaterra e, especialmente, dos Estados Unidos. Para evitá-la, os acionistas do banco, o público e o governo eram convocados a exercer o controle e a fiscalização da instituição (FRANCO, 1846c, p. 2). O controle de acionistas e do público e a fiscalização governamental também serão invocados quando Souza Franco tratar da questão em âmbito nacional. O papel do governo na regulação dos bancos será extensamente trabalhado nesse caso. Como afirma Schulz (2013), apesar de acusado de inflacionista pelos adversários, o rigor nas operações bancárias e o lastro da emissão sempre o preocuparam;

b) externamente, o perigo vinha de duas frentes. A primeira correspondia ao excesso de intervenção, sob o qual o banco correria o risco de uma tomada arbitrária de seus fundos, segundo Souza Franco, sempre com o pretexto da necessidade pública. Ele afirma que isso é mais fácil de acontecer em governos despóticos - cita o exemplo da Turquia - do que em governos representativos, por conta da opinião pública. No caso dos representativos, só mesmo a urgência pública, um caso de guerra, por exemplo, justificaria o recurso aos fundos bancários. A segunda frente correspondia às eventuais desordens sociais, como roubo e incêndio, e outros riscos como furto, falsificação ou quebra fraudulenta de um devedor mal afiançado, mas reconhecia que nesses casos haveria um risco inerente ao capital empregado em qualquer atividade. Nos bancos, o efeito de eventuais perdas seria até mais leve do que para um particular, posto que seriam divididas entre todos os acionistas.

É interessante notar que Souza Franco cita exemplos estrangeiros concretos para ilustrar os perigos que os bancos podem correr, indicando que a experiência internacional chegava ao país e lhe era familiar. Contudo, os perigos também guardavam estreita relação com a situação nacional. O perigo do despotismo e da intervenção governamental ilustra o movimento do partido conservador de cen- 
tralização do poder político na corte (MATTOS, 2004), já o das desordens sociais está relacionado às agitações do período regencial e início do segundo reinado, como a que o próprio Souza Franco teve que lidar em sua breve e conturbada passagem pela presidência da província de Alagoas em 1844.

A possibilidade de se criar e manter o banco na província é o assunto dos dois últimos artigos. O fundo do banco seria formado parte pelo capital entesourado e parte pelo valor arrecadado com a venda das primeiras ações. Negociantes, proprietários e lavradores "com crédito na praça" deveriam ser os primeiros a comprá-las e a dar o exemplo. Souza Franco calculava entre trinta e cinquenta contos o capital necessário para o início das operações do banco e não considerava difícil conseguir essa soma, dado o cálculo de mais ou menos mil contos disponíveis na província. Finalmente, aponta como terceira alternativa para obtenção de recursos a criação de caixas econômicas filiais ao banco das quais a matriz poderia tomar dinheiro a juros em benefício de si própria e de poupadores pobres (FRANCO, 1846d). Portanto, a constituição do capital para a criação do banco na província não seria grande problema.

Quanto à sua manutenção, o banco criado poderia ser seguro e rentável? Souza Franco pensava que o banco seria um bom negócio, porque poderia emprestar a juros mais baixos dos que os praticados naquela altura na província e, com isso, garantiria demanda suficiente para a segurança e rentabilidade das operações. Segundo ele, haveria na província demanda não só para empréstimos novos, como também para a troca de dívidas mais caras pelos empréstimos mais baratos oferecidos pelo banco (FRANCO, 1846e). Enfim, conclui o artigo com uma exortação à criação do banco do Pará: "[...] à vista disso um Banco e quanto antes, em benefício de todos, e especialmente dos que têm capitais disponíveis, e do Comércio em geral [...]" (FRANCO, 1846e, p. 3).

Como já adiantado, o banco do Pará foi criado em 1846 para atender às "precisões da indústria provincial" (FRANCO, 1984, p. 41). Do que foi exposto, é possível perceber, nos argumentos de Souza Franco, a influência das ideias da escola bancária inglesa e de Mata Albuquerque. Elas aparecem sob a forma da defesa de uma emissão monetária que fosse capaz de acompanhar o ritmo dos negócios, da substituição da circulação metálica por papel e do lastro parcialmente metálico. Apresentam-se também na preocupação com o excesso de emissão e, especialmente, no caso do Pará, no diagnóstico de que o entesouramento é um entrave à realização dos negócios e no desenvolvimento da província. Essas ideias também aparecerão em Os bancos do Brasil, com diferenças que marcam a mudança da dimensão em que a questão dos bancos será tratada, do âmbito regional para o nacional. 


\section{A Reforma do Sistema Bancário Nacional}

Em Os bancos do Brasil, escrito em 1848, Souza Franco (1984) faz um diagnóstico do sistema bancário brasileiro à época, a fim de propor uma reorganização bancária no país mais condizente com sua realidade econômica e política, equivale dizer com emissão monetária plural e baseada parcialmente em títulos. O diagnóstico feito para a província do Pará dois anos antes parece se aplicar ao contexto nacional. Souza Franco apresenta seu livro para um país novo e carente de capitais. Para resolver o problema, seria preciso criar instituições de crédito que pudessem colocar os capitais desempregados a serviço da atividade econômica. Repete-se, em âmbito nacional, a questão do entesouramento, mas não somente, pois isso não seria suficiente para resolver a escassez de moeda e crédito. Também volta à baila a necessidade de bancos emissores.

O contexto em que Souza Franco escreve é o de criação de bancos no Brasil. Por isso dizia que, embora os depósitos bancários ainda não fossem um hábito como nos Estados Unidos e na Europa, a intermediação já era aceita no Brasil na década de 1840. Entretanto, era preciso ajustar a situação dos bancos existentes, sobretudo na questão da regulamentação. Além de não haver legislação específica para os bancos, alguns funcionavam irregularmente, como era o caso do Banco Comercial do Rio de Janeiro mencionado anteriormente. Assim, o principal problema nesse campo era a ausência de regulamentação bancária. Sem ela, dizia Souza Franco, estimulados apenas pelo interesse privado, os bancos poderiam ser nocivos ao governo, aos clientes e aos próprios acionistas (FRANCO, 1984, p. 9).

Essa passagem reforça a ideia de que Souza Franco não era adepto dos bancos livres e revela uma crítica de fundo moral ao comportamento individualista dos banqueiros, que será aprofundada adiante. Além disso, o receio de uma crise bancária derivada da ausência de legislação para os bancos pode estar relacionado aos eventos ocorridos em 1837 nos Estados Unidos, país que lhe serviu de modelo.

A partir da premissa exposta na abertura do livro, Souza Franco passa a analisar cada banco constituído no país. Essa análise nos será proveitosa para retirarmos de cada caso aquilo que se constituiria na orientação mais geral apresentada posteriormente na proposta de reforma do sistema bancário. Essa pequena recuperação é interessante porque indica que o conhecimento e a análise do caso brasileiro também eram importantes para a formulação da reforma, não se tratando, portanto, de mera importação e aplicação de ideias estrangeiras sem maiores considerações com a realidade nacional.

No caso do primeiro Banco do Brasil, que funcionou de 1808 a 1829, Souza Franco curiosamente não atribui ao Estado a responsabilidade final por sua falência. Pelo contrário, culpa a inépcia e a má-fé de seus administradores, que 
se perderam em meio a créditos podres e não cobrados, corrupção e sigilo das operações. A solução para sua crise, portanto, não seria desatrelar o banco do Estado - aliás, Souza Franco não via problema nessa relação -, mas dar inteira publicidade a todos os atos dos bancos em geral, tal como acontecia em outros países, para garantir a boa gestão de suas operações, pois assim precaveria governo e acionistas e evitaria especulação sobre sua situação. Concretamente, significaria a publicação periódica de relatórios e balanços com frequência pelo menos semanal, como indicava Robert Peel na Inglaterra (FRANCO, 1984, p. 30), em que pese a possibilidade de fraude nas informações. Vale notar uma referência clara à experiência inglesa. Outro elemento importante nesse tipo de controle seria a desejável concorrência no setor.

O caso do Banco Comercial do Rio de Janeiro, além de representar o não cumprimento da frágil legislação existente, como vimos, também ilustra o problema da insuficiência de depósitos bancários no Brasil vis-à-vis à necessidade de crédito da economia. Por isso, Souza Franco discordava da determinação governamental de restringir a emissão do banco por meio da imposição de um limite para sua emissão, do aumento do valor das notas emitidas e do encurtamento de seu prazo. O governo tentava, com isso, dificultar a entrada em circulação das notas emitidas pelo banco. Por outro lado, com essa restrição, o banco pouco poderia fazer pelo comércio, pois, tendo apenas os depósitos como base dos empréstimos, haveria pouco capital disponível e, assim, o banco pagaria pouco aos acionistas e emprestaria pouco à praça e ao governo. É preciso lembrar que, na visão de Souza Franco, a oferta de crédito baseada nos recursos depositados nos bancos teria que ser completada pela emissão bancária. A base da afirmação da insuficiência de crédito no Brasil, sobretudo na corte, vem da comparação com Nova Iorque (FRANCO, 1984, p. 31).

Embora fosse favorável ao lastro em títulos, Souza Franco criticou a proposta do Banco da Bahia de usar ações do próprio banco como garantia de descontos, pois considerava que isso reduziria o capital real do banco e o substituiria por um capital em boa medida fictício. Souza Franco afirma que, nos Estados Unidos, onde essa prática foi permitida, o resultado era que os bancos integralizavam apenas parte do capital e faziam a maior parte das operações de empréstimo sob a garantia de ações do próprio banco. De fato, Hammond (1967) se refere à ausência de regulamentação sobre as reservas bancárias como uma das causas da crise bancária de 1837. Dessa vez o exemplo veio da América do Norte, indicando mais uma vez a experiência estrangeira como base para se pensar a realidade nacional. Por fim, no caso do Banco de Pernambuco, criticou a pretensa obrigatoriedade de depósitos no banco. Para ele, a atração de capitais não poderia ser compulsória, mesmo no contexto em que a cultura do depósito bancário não estivesse desenvolvida. 
Em suma, regulação, controle e publicidade das operações bancárias, concorrência, necessidade de emissão garantida parcialmente por títulos públicos e liberdade de depósitos serão elementos que aparecerão na proposta de reforma bancária. Contudo, é preciso antes considerar o diagnóstico do sistema bancário nacional feito por Souza Franco.

\subsection{Diagnóstico}

O diagnóstico é, basicamente, um levantamento do que Souza Franco considera defeitos de organização dos bancos do império. Evidentemente, esses defeitos são os que aparecem aos olhos de um defensor da pluralidade de emissão e do lastro parcialmente metálico. Vale lembrar, ainda, que, em 1848, sobe o gabinete saquarema, chefiado por Joaquim José Rodrigues Torres. Portanto, é preciso considerar também que Souza Franco fala a partir da oposição política ao gabinete, especialmente na matéria sobre bancos.

Entretanto, antes de entrar propriamente na caracterização dos defeitos, retoma o discurso sobre a utilidade dos bancos e quem teria interesse nessa atividade. Sobre a utilidade, revisita argumentos, que usou nos artigos de 1846, de que os bancos atraem e reúnem capitais entesourados e, portanto, desempregados (FRANCO, 1984, p. 56). Avança ao salientar a força da reunião de capitais em oposição à fragilidade de capitais fragmentados. Contudo, diz Souza Franco, os bancos só são úteis na medida em que suas operações interessam ao conjunto da sociedade, e não de apenas uma de suas classes. Nesse ponto, ele distingue os interesses de acionistas, clientes e governo, buscando definir o que seria um equilíbrio de interesses. Por exemplo, os dividendos pagos aos acionistas não deviam ser altos demais e deviam gravitar o juro corrente, naquela altura em torno de $8 \%$ ao ano; os empréstimos deviam ter juros módicos e prazos adequados; o crédito devia funcionar como motor do crescimento econômico (SCHULZ, 2013).

Souza Franco não era um ingênuo. O problema estava em conciliar interesses claramente conflitantes, sobretudo, entre o banco, os depositantes e os tomadores de empréstimos. Se ao banco interessava obter o maior ganho possível com a cobrança de juros, ainda que isso significasse assumir maiores riscos, aos depositantes interessava receber juros sobre os recursos depositados com o menor risco e aos tomadores interessava pagar a menor taxa de juros. Diante do conjunto de possibilidades contraditórias, a conciliação não surgiria naturalmente, cabendo ao governo, por meio da regulamentação e fiscalização, intermediar o conflito de interesses e a preservação dos interesses da economia como um todo.

Para Souza Franco, a utilidade dos bancos e o interesse das diferentes frações de classe nessa atividade não poderiam ser cumpridos adequadamente, sobretudo por conta de vícios de organização que diziam respeito à legislação e à adminis- 
tração bancária. O primeiro defeito, referente à legislação, era sujeitar os bancos existentes no país às regras que regiam bancos organizados com fundo da capital metálico, embora aqueles pudessem ser constituídos com fundo de capital em papel-moeda. Por que era um defeito? Porque as regras para bancos com fundo de capital metálico eram mais restritivas ao crédito. Além disso, sem uma legislação que desse segurança a empréstimos de prazos mais longos, predominavam os de curto prazo, frequentemente de três a quatro meses, que atendiam bem ao comércio, mas não eram adequados à agricultura e manufatura. $\mathrm{O}$ exemplo citado nesse caso é o do Banco Comercial do Rio de Janeiro. Já os Bancos da Bahia, Pará e Maranhão procuravam atender os prazos demandados pelo mercado, isto é, mais longos (FRANCO, 1984, p. 58). Segundo Souza Franco, o problema era seguir uma prática restritiva que valia para os bancos que se organizavam sob base metálica, como na Inglaterra e França, mas não valia para os bancos brasileiros, organizados sob base fiduciária. Uma vez que os bancos brasileiros da época utilizavam papéis do Tesouro como reserva, seria improvável uma corrida aos bancos para trocar papel por papel, a não ser que houvesse uma grave perda de confiança no banco, e assim, os empréstimos poderiam ser feitos com prazo mais longo (FRANCO, 1984, p. 61). A solução da reforma de letras para equacionar o problema era considerada por ele inconveniente. O ideal era que os empréstimos fossem mais longos e com juros mais altos, tal como recomendava a lei do estado de Nova Iorque, de 2 abril de 1829, a chamada Safety Fund Act, e a prática do Banco da Inglaterra (FRANCO, 1984, p. 63).

O segundo defeito, referente à administração, considerava o problema dos juros altos e da excessiva distribuição de dividendos. Problemas adicionais surgiam com os bancos que, além de fazer operações de empréstimo e depósitos, também emitiam bilhetes. Era o caso dos bancos brasileiros à época e dos bancos dos Estados Unidos, França e Inglaterra (FRANCO, 1984, p. 59). O principal desafio para esses bancos seria ter uma administração que conseguisse equilibrar o interesse dos acionistas na emissão de notas e a garantia de conversibilidade das notas emitidas e devolução dos depósitos. Em outras palavras, por um lado, o aumento da emissão poderia levar a um aumento do lucro e da distribuição de dividendos aos acionistas, por outro lado poderia comprometer a conversibilidade e a solvência do banco. Apesar de papelista, como já mencionado, a conversibilidade em metal ou papel seria importante para criar a confiança do público no banco.

É a esse equilíbrio de interesses de acionistas, depositantes e da sociedade em geral que Souza Franco se refere ao longo de seu diagnóstico. O equilíbrio, porém, não seria alcançado simplesmente pela conscientização dos administradores dos bancos. Era preciso que o Estado atuasse sobre sua organização e operação por meio de regulamentação. A regulamentação era justificada pelo caráter público dos bancos de emissão, uma vez que seus bilhetes interferiam no mercado 
monetário, e pelos riscos de abusos. Para discutir como deveria ser feita, Souza Franco lança mão de exemplos detalhados dados pela legislação inglesa e estadunidense. De maneira geral, o movimento era de imposição de restrições tanto ao estabelecimento quanto à operação dos bancos nesses países, e Souza Franco reforça a ideia de que o Brasil deveria aprender com a experiência dos pioneiros: "[...] e seria suma imprudência que o Brasil, que ora entra como que de novo nesta carreira, a fosse percorrer toda inteira, quando deve aproveitar o fruto da experiência dos que nela o precederam [...]" (FRANCO, 1984, p. 68). Notam-se aí novamente dois elementos importantes do debate econômico brasileiro da época: o recurso à experiência, sobretudo por papelistas, e a referência estrangeira.

Diante desses defeitos, seria necessária uma reforma para corrigi-los, evitar abusos tais como os ocorridos nos Estados Unidos e fazer dos bancos verdadeiros motores do crescimento econômico do império (FRANCO, 1984, p. 78).

\subsection{Proposta}

A reforma proposta por Souza Franco passa por questões centrais da organização bancária e monetária do país. São cinco questões que abrangem: a) a competência da autorização do funcionamento de bancos; b) a pluralidade ou monopólio de emissão; c) a natureza pública ou privada dos bancos; d) o lastro metálico parcial ou total; e) a definição de um meio circulante formado por notas do tesouro ou dos bancos.

Para Souza Franco, os bancos deveriam ser autorizados a funcionar pelo governo, portanto, não se pode afirmar que era um apoiador dos bancos livres. $\mathrm{O}$ segundo passo seria definir a que instância governamental caberia a autorização. Apesar de defensor dos interesses provinciais, ele indica a assembleia geral e o governo central, por meio do ministério da fazenda, como instâncias competentes nesse caso, porque moeda e bancos seriam assuntos de interesse e alcance geral. Estava ciente do modelo dos Estados Unidos, que atribuía a autorização às assembleias provinciais, mas afirmava que, nesse caso específico, o modelo não servia para o Brasil. Essa é mais uma evidência de que não se tratava de mera importação de modelos ou ideias sem maior juízo crítico. ${ }^{1}$

A discussão sobre pluralidade ou monopólio de emissão surge sob a alternativa entre um banco emissor na corte com filiais nas províncias ou bancos emissores provinciais independentes. O maior problema da primeira alternativa, segundo Souza Franco, era geográfico, pois “[...] seria insuperável o problema das grandes distâncias, aumentadas terrivelmente pelas dificuldades e demoras nas comuni-

1 O Decreto $\mathrm{n}^{\circ} 575$, de 10 de janeiro de 1849 , regulava as sociedades anônimas, inclusive instituições bancárias. De acordo com o decreto, o ministério da fazenda seria o responsável por autorizar o funcionamento dos bancos (BRASIL, 1850). Para a legislação bancária do império posterior a 1850, ver Gornati (2013). 
cações [...]" (FRANCO, 1984, p. 83). Além disso, estabelecer um poderoso banco na corte, apesar das filiais nas províncias, significaria dar força demais ao poder central, o que seria incompatível com o sistema representativo. Sua solução para o problema seria a criação de bancos provinciais ou bancos por círculos de duas ou mais províncias, conforme a ligação de seus mercados.

Ambos os argumentos utilizados por Souza Franco serão utilizados no debate parlamentar de 1853 sobre a criação do Banco do Brasil. A crítica ao reforço do poder central em detrimento das províncias deve ser entendida no contexto da disputa política mais ampla entre conservadores e liberais. No período em que ocupou o ministério da fazenda, entre 1857 e 1858, ele reverteu a política monoemissora dos conservadores e colocou em prática a pluralidade bancária (GAMBI, 2015).

Os bancos deveriam ser preferencialmente de natureza privada. O Estado só deveria ser acionista de bancos que não tivessem condições de se organizar sem sua ajuda em locais que demandassem moeda e crédito, uma vez que seu objetivo seria o aumento da riqueza pública. Caso fosse acionista de um banco, passaria também a pensar nos lucros da instituição, desviando-se de seu objetivo maior. $\mathrm{O}$ governo, todavia, teria um importante papel na fiscalização e proteção dos bancos, como já comentado anteriormente. Souza Franco é contra a não intervenção governamental nos bancos e diz que essa posição tem força justamente por conta do excesso de intervenção e dos excessos cometidos por governos absolutos sobre instituições bancárias. Não seria o caso de governos representativos, como os Estados Unidos. No Brasil, ele se refere aos interesses de partido possivelmente referindo-se aos conservadores saquaremas. Ele estava certo, pois, em 1853, seu temor se concretizará na organização do Banco do Brasil.

Na questão do lastro metálico, Souza Franco é prático. Dadas as circunstâncias do império, o lastro deveria ser apenas parcialmente metálico, complementado por títulos da dívida pública, e a emissão deveria ser feita por bancos, e não pelo Tesouro: "[...] não há a menor dúvida de que o papel de bancos bem organizados é preferível ao não realizável do Governo [...]" (FRANCO, 1984, p. $88,109)$. A circulação de moeda parcialmente metálica, emitida por bancos, seria mais adequada à flexibilidade do mercado, à disponibilidade de metais e ao alcance geográfico das emissões, dando maior capilaridade à circulação.

Em suma, Souza Franco propunha em sua reforma a autorização governamental para a criação de bancos pelo legislativo e executivo, a pluralidade de emissão, a preferência por bancos privados, a emissão parcialmente metálica e a circulação composta por notas bancárias.

A reforma de Souza Franco era bancária e monetária. Nela, ainda havia uma parte para tratar da substituição das notas do Tesouro em circulação e do crédito rural e hipotecário. Não entraremos nessa parte, porque se tratam de questões 
mais operacionais. O cerne da prática baseada em teorias econômicas ou experiências estrangeiras está apresentado na discussão anterior. A influência do debate inglês, da escola bancária, é notada nos argumentos em favor da pluralidade, da moeda bancária e do lastro parcialmente metálico. Não há referência a nomes, mas o próprio Souza Franco aponta a razão disso:

Não resta, portanto, ao que parece, dúvidas sobre as vantagens dos bancos propostos e segurança dos capitais neles empregados. E deixo de sustentar grande parte das doutrinas em que se baseiam suas disposições, porque ou me parecem geralmente reconhecidas, ou se depreendem dos diversos capítulos deste opúsculo [Os bancos do Brasil] (FRANCO, 1984, p. 110). ${ }^{2}$

Já os casos concretos são abundantemente citados. Destacam-se, como era de se esperar, os dos Estados Unidos e da Inglaterra, mas há referências também à experiência de outros países europeus, como a França.

Vale destacar que, apesar de informada por referências estrangeiras, a argumentação de Souza Franco era adequada à realidade brasileira, como ele mesmo reconhece. Nesse contexto, discute-se o lastro metálico em um quadro de escassez de metais, a pluralidade bancária em um quadro de disputa política e partidária entre províncias e corte e a preferência por bancos privados e emissão bancária em um ambiente em que o Estado ainda estava em construção. Esses são elementos da discussão sobre moeda e bancos no âmbito nacional que reforçariam o argumento de que na periferia havia adaptação das ideias econômicas estrangeiras e de que o debate econômico no império brasileiro não fugia a essa regra.

\section{Considerações Finais}

Souza Franco foi, sem dúvida, um dos principais e mais influentes debatedores da questão monetária e bancária em meados do século XIX no Brasil. Pelas ideias que defendia nesse campo, pode-se dizer que era um papelista, defensor de uma moeda parcialmente lastreada em metal. Contudo, não um radical do papel-moeda fiduciário. Além disso, sustentava a necessidade de regulamentação estatal sobre a criação e operação dos bancos, não sendo, portanto, um adepto dos bancos livres. Sua posição, nesses aspectos, era próxima da escola bancária inglesa.

Representante da província do Pará na assembleia geral, sustentava a pluralidade bancária para que a moeda e o crédito chegassem de maneira adequada às mais distantes regiões do império. Na década de 1840, o problema da escassez

2 De fato, não se tratava de ignorância. Quando necessário ao discurso, Souza Franco recorre à citação de autores estrangeiros. Eles aparecem nos debates parlamentares. Ver, por exemplo, o debate sobre a provincialização do meio circulante em Sáez (2013, p. 50). 
de moeda e crédito se fazia sentir em sua província, e Souza Franco escreveu uma série de artigos apresentando argumentos para a criação de um banco local. A argumentação exposta em uma série de cinco artigos publicada no jornal Treze de Maio, em 1846, antecipava em boa medida a de 1848, quando foi publicado Os bancos do Brasil.

O objetivo de ambos os escritos era refletir sobre a criação de bancos no país, porém os artigos tratavam da questão em nível regional e o livro em nível nacional. Ao compará-los, é possível notar que os argumentos utilizados para sustentar a criação de um banco provincial são mais ou menos os mesmos utilizados para defender a criação de bancos por todo o império. Isso não surpreende, pois o sistema nacional de bancos proposto por Souza Franco estava baseado no lastro parcialmente metálico e na pluralidade emissora e deveria, portanto, comportar bancos provinciais.

Os bancos seriam o núcleo da engrenagem que moveria a economia brasileira à época. Schulz acerta ao dizer que Souza Franco pensava os bancos como motores do crescimento. Seria preciso especificar, todavia, o sentido do crescimento econômico no contexto do império. Não se tratava de um crescimento destinado a promover mudanças estruturais, mas sim obediente aos limites da economia mercantil e escravista. Embora Souza Franco falasse de incentivo à manufatura, a preocupação fundamental era com a agricultura e o comércio. Embora fosse simpático ao abolicionismo, não discute a escravidão. A monarquia e a propriedade fundiária tampouco são questionadas. Os bancos faziam parte, portanto, de uma engrenagem construída pela elite do império para manter a estrutura econômica e política, e não para mudá-la. Em que pesem as divergências de meio entre os partidos políticos brasileiros, o fim era o mesmo: o progresso e a civilização do império.

É no debate sobre os meios de se atingir o progresso que Souza Franco, membro do partido liberal, se destaca na questão bancária e se opõe, de modo bastante claro, às posições dos políticos chamados metalistas, muitos deles ligados ao partido conservador. Formado em Direito pela Faculdade de Olinda, suas ideias coincidem em boa medida com as do primeiro professor da cátedra de economia política dessa faculdade, Mata Albuquerque, que, por sua vez, foi influenciado por James Mill e pela experiência escocesa. De fato, a coerência das ideias econômicas de Souza Franco pode ser observada desde a apresentação dos artigos de 1846 até os debates monetários da década de 1860.

Ao analisar essas ideias, notam-se influências estrangeiras. Autores não são citados com frequência, mas é possível perceber elementos da escola bancária inglesa. A escassez de citações de autoridades era uma opção de Souza Franco e não ignorância ou falta de erudição de sua parte, pois sua principal preocupação, assim como de outros debatedores da época, era eminentemente prática. O objetivo maior era resolver problemas reais e, nessa altura, é preciso lembrar que boa 
parte dos debatedores das ideias econômicas no Brasil eram também políticos. Pode-se dizer que, no limite, não havia preocupação teórica, isto é, a preocupação em formular teoria econômica. Por isso, proliferam em seus textos e discursos referências a casos concretos, sobretudo dos Estados Unidos e da Inglaterra, que pudessem ser aplicados ao caso brasileiro.

Vale dizer, entretanto, que seu ponto de vista é regional e nacional. O problema do entesouramento e da escassez metal, por exemplo, eram realidades da província e do país. A argumentação de Souza Franco apresentada nos textos analisados neste trabalho revelam que as ideias econômicas estrangeiras eram conhecidas, assim como as experiências vindas do exterior. Esse conhecimento era assimilado criticamente e adaptado às circunstâncias regionais e nacionais. Assimilação crítica e adaptação eram imperativos no debate de ideias que tinha em vista a pavimentação de soluções para problemas concretos da economia imperial. No caso de Souza Franco, suas ideias se materializarão em sua passagem pelo ministério da fazenda pouco menos de uma década depois da publicação de seu livro.

Finalmente, considerar as ideias de Souza Franco baseadas em assimilações críticas e adaptações de ideias e experiências estrangeiras não implica dizer que elas significassem mudanças qualitativas na estrutura econômica e política do império. Pelo contrário. Talvez seja possível dizer que já havia consciência dos problemas nacionais, contudo a preocupação principal era a manutenção de uma sociedade de corte nos trópicos.

\section{Referências}

BEAUCLAIR, G. M. O. A construção inacabada: a economia brasileira (1820-1860). Rio de Janeiro: Vício de leitura, 2001.

BRASIL. Collecção das Leis do Imperio do Brasil de 1849. Rio de Janeiro: Typographia Nacional, 1850.

CÂMARA DOS DEPUTADOS. Annaes do Parlamento Brazileiro. Camara dos Srs. Deputados. Primeiro anno da Décima Legislatura. Sessão de 1857. Tomo 2. Rio de Janeiro: Typographia Imperial e Constitucional de J. Villeneuve e Comp., 1857.

CÂMARA DOS DEPUTADOS. Annaes do Parlamento Brazileiro. Camara dos Srs. Deputados. Primeiro Anno da Oitava Legislatura. Sessão de 1850. Tomo II. Rio de Janeiro: Typographia H. J. Pinto, 1879.

CARDOSO, J. L. História do pensamento econômico português: temas e problemas. Lisboa: Livros Horizonte, 2001.

CARDOSO, J. L. Pensar a economia em Portugal: digressões históricas. São Paulo: Difel, 1997.

CORRÊA, F. R. C. Rompendo com a economia política clássica no século XIX: a recepção das ideias de Henry Dunning MacLeod no Brasil. In: XI CONGRESSO BRASILEIRO DE 

EMPRESAS, 2015, Vitória. Anais eletrônicos [...]. Vitória: ABPHE/UFES, 2015.

FONSECA, P. C. D. Gênese e precursores do desenvolvimentismo no Brasil. In: BASTOS, P. P. Z.; FONSECA, P. C.D. (org.). A era Vargas: desenvolvimentismo, economia e sociedade. São Paulo: Unesp, 2012.

FRANCO, B. S. Os bancos do Brasil: sua história, defeitos da organização atual e reforma do sistema bancário. Brasília: Editora Universidade de Brasília, 1984.

FRANCO, B. S. Demonstra-se a necessidade de um Banco Commercial nesta Praça. Treze de Maio, Belém, edição 581, 1846a.

FRANCO, B. S. A necessidade de um Banco Commercial. Continuação do n. 581. Treze de Maio, Belém, edição 582, 1846b.

FRANCO, B. S. Continua a demonstração da necessidade de um Banco Commercial nesta Praça. Treze de Maio, Belém, edição 585, 1846c.

FRANCO, B. S. A necessidade de um Banco Commercial nesta Praça; continuado do n. 585. Treze de Maio, Belém, edição 587, 1846d.

FRANCO, B. S. A necessidade de um Banco Commercial nesta Praça; continuado do n. 587. Treze de Maio, Belém, edição 591, 1846e.

FURTADO, C. Formação econômica do Brasil. São Paulo: Cia das Letras, 2007.

GAMBI, T. F. R. O banco da Ordem: política e finanças no império brasileiro. São Paulo: Alameda, 2015.

GORNATI, G. Legislação bancária no Brasil Império: o debate jurídico sobre a função bancária na década de 1850. 2013. Dissertação (Mestrado em Direito) - Faculdade de Direito, Universidade de São Paulo, São Paulo, 2013.

GREMAUD, A. P. A penetração da economia política no Brasil e seu ensino durante o período imperial: Cairu, Mata Albuquerque e Lourenço Loureiro. Textos para Discussão. Série Economia, n.13, 2000.

GREMAUD, A. P. Das controvérsias teóricas à política econômica: pensamento econômico e economia brasileira no segundo império e na primeira república (1840-1930). 1997. Tese (Doutorado em Economia) - Faculdade de Economia, Administração e Contabilidade, Universidade de São Paulo, São Paulo, 1997.

GUIMARÃES, C. G. O Império e os bancos comerciais do Rio de Janeiro na segunda metade do século XIX: os casos do Banco Mauá, MacGregor $\mathcal{E}$ Co., do Banco Rural e Hipotecário do Rio de Janeiro, e do Comercial e Agrícola. In: CONGRESSO BRASILEIRO DE HISTÓRIA ECONÔMICA, 3.; CONFERÊNCIA INTERNACIONAL DE HISTÓRIA DE EMPRESAS, 4., 1999, Curitiba. Anais eletrônicos [...]. Curitiba: ABPHE/UFPR, 1999.

HAMMOND, B. Banks and politics in america from the revolution to the civil war. Nova Jersey: Princeton University Press, 1967. 
HUGON, P. A economia política no Brasil. In: AZEVEDO, F. (org.). As ciências no Brasil. 2. ed. Rio de Janeiro: Ed. UFRJ, 1994. v. 2.

LEVY, M. B.; ANDRADE, A. M. R. Fundamentos do sistema bancário no Brasil: 1834-1860. Estudos Econômicos, v.15,n. especial, p.17-48, 1985.

MACEDO, J. M. Anno biographico Brazileiro. Rio de Janeiro: Tipographia e Lithographia do Imperial Instituto Artístico, 1876.

MARX, K. O capital. Livro 1. São Paulo: Boitempo, 2013.

MATTOS, I. R. O tempo saquarema: a formação do Estado imperial. São Paulo: Hucitec, 2004.

MORAES, J. M. Relatório presidente de província. Discurso recitado pelo Exm ${ }^{\circ}$ Sñr. Doutor João Maria de Moraes vice-prezidente da província do Pará na abertura da segunda sessão da quarta legislatura da Assembléa Provincial no dia 15 de agosto de 1845. Pará: Typ. de Santos E Filhos, 1845.

OLIVEIRA, G. B. M. . A construção inacabada: a economia brasileira, 1828-1860. Rio de Janeiro: Vício de Leitura, 2001. v. 1.

PELÁEZ, C. M.; BULHÕES, O. G. Introdução a propósito da intermediação financeira. In: FRANCO, B. S. Os bancos do Brasil: sua história, defeitos da organização atual e reforma do sistema bancário. Brasília: Ed. Universidade de Brasília, 1984.

RIDINGS, E. Business interest groups in nineteenth-century Brazil. Cambridge: Cambridge University Press, 1994.

SAES, F. A. M. Crédito e bancos no desenvolvimento da economia paulista, 1850-1930. São Paulo: IPE/USP, 1986.

SÁEZ, H. E. L. Nas asas de Dédalo: um estudo sobre o meio circulante no Brasil entre os anos de 1840 a 1853. 2008. Dissertação (Mestrado em História Econômica) - Faculdade de Filosofia, Letras e Ciências Humanas, Universidade de São Paulo, 2008.

SÁEZ, Hernán Enrique Lara. O tonel das danaides: um estudo sobre o debate do meio circulante no Brasil entre os anos de 1850 a 1866 nas principais instâncias decisórias. 2013. Tese (Doutorado em História Econômica) - Faculdade de Filosofia, Letras e Ciências Humanas, Universidade de São Paulo, 2013.

SALOMÃO, I. C. O desenvolvimento em construção: um estudo sobre a pré-história do pensamento desenvolvimentista brasileiro. 2013. Tese (Doutorado em Economia) Faculdade de Ciências Econômicas, Universidade Federal do Rio Grande do Sul, 2013.

SCHULZ, J. Souza Franco and banks of issue as engines of growth. História e Economia, v.11, 2013.

TREZE DE MAIO. Belém: [S.n.], edição 551, 1845.

VASCONCELLOS, Barão e SMITH DE VASCONCELLOS, Barão. Archivo nobiliarchico brasileiro. Lausanne: Imprimerie La Concorde, 1918. 
VILLELA, A. A. The quest for gold: monetary debates in nineteenth century Brazil. Brazilian Journal of Political Economy, v. 21, n. 4 (84), 2001.

VILLELA, A. A. The political economy of money and banking in Imperial Brazil 1850-1870. 1999. Tese (Doutorado em História econômica) - London School of Economics and Political Science, 1999.

Recebido em: 22/09/2017. Aceito em: 19/12/2017. 